\title{
An Initial Investigation of the Effects of Mulch Layers on Soil- Dwelling Arthropod Assemblages in Vineyards
}

\author{
P. Addison*, A.H. Baauw and G.A. Groenewald \\ Department of Conservation Ecology and Entomology, Faculty of AgriSciences, Stellenbosch University, Stellenbosch, South \\ Africa
}

Submitted for publication: May 2013

Accepted for publication: August 2013

Key words: Pitfall traps, insects, Collembola, Formicidae, straw, compost, woodchips, ecosystem services

\begin{abstract}
The use of mulches is gaining worldwide attention in a number of different crops, including vineyards. However, the effects of mulches on arthropod assemblages are not well documented. We therefore conducted an initial investigation into the effects of three different types of mulch on arthropod assemblages in vineyards. Sampling took place from March to June 2010 on four wine grape farms in the Stellenbosch/ Paarl region using pitfall traps. All arthropods were identified to family level and classified into functional feeding groups. A total of forty different families of springtail (Collembola) and insect (Insecta) were recorded. Cluster analysis indicated a high degree of similarity between the mulch sites and also between the control sites, based on soil-dwelling arthropod diversity. Springtails and ants were most abundant and could be used as reference organisms for future, larger-scale studies on mulches.
\end{abstract}

\section{INTRODUCTION}

Biodiversity loss and environmental degradation through increasing anthropogenic pressure are two factors that currently concern ecologists (Tilman et al., 2002). At the same time, crop production enhancements, reduction of costs and increase in yields are key issues in the agricultural sector (Tilman et al., 2002). For long, these two were seen as conflicting sectors (Kim \& Weaver, 1994; Henle et al., 2008). A characteristic example is found in pesticides, which are used in order to benefit crop production. Simultaneously, they are among the major drivers of biodiversity loss and environmental degradation (Altieri, 1999; Henle et al., 2008).

Solutions to this growing conflict are found in integrated pest management (IPM). IPM aims to incorporate the available knowledge of the crops, their related pests and beneficial species into management programmes. Those management programmes are designed to reduce synthetic chemical inputs as much as possible, while supporting the use of ecosystem services, thereby enhancing crop production (Stern et al., 1959; Sandhu et al., 2010). Consequently, an increasing movement away from pesticides to using biologically based pest management methods can be observed (see Flint, 2012). These methods work mainly by promoting beneficial organisms and crop health. Beneficial organisms may promote crop health directly (e.g. through pollination) or indirectly. The indirect impact of organisms works via biotic (e.g. enemies of crop pest species) and abiotic (e.g. earthworms improve soil qualities) conditions (Wardle et al., 2004; Zehnder et al., 2007).

Mulching is a method originally designed to benefit (fruit) crops via abiotic conditions directly. Mulch can consist of various materials; examples are compost, straw, woodchips and black plastic. By applying an additional mulch layer on top of the soil around the crops, abiotic factors such as soil humidity, temperature and structure are improved (Shangning \& Unger, 2001; Cook et al., 2006; Ramakrishna et al., 2006) and, as a consequence, horticultural conditions. Increasing the organic matter in crop soils was found to improve the pest resistance of crops due to increased soil microbial activity, improve nutrient balance and reduce nitrogen content (Altieri \& Nicholls, 2003). A lesser-studied aspect of the effect of mulches is their influence on the arthropod communities in the soil and their feedback on crop production. Indications are that mulching potentially interferes with oviposition preferences, host plant discrimination and host location of insect pests (Zehnder et al., 2007).

Mulching materials are likely to influence soil microhabitats, and therefore the composition of the soilinhabiting arthropod community, in different ways. Reduced soil temperatures could have an impact on pest ants in vineyards (Addison \& Samways, 2006; Smith, 2007). Thomson and Hoffman (2007) also found an increase of natural enemies when using straw or compost ground cover, and an increase of soil macro-invertebrates with compost

*Corresponding author: E-mail: pia@sun.ac.za

Aknowledgements: We thank HortGro Science, Winetech and THRIP, for funding, Dr Ken Pringle, for assistance with the statistical analyses, and all the farm managers, for assisting us with trial sites. Thanks also go to Siya Ntuli, for technical support, and Prof. Henk Geertsema, for assisting with insect identifications 
in vineyards in Australia. Fruit weevils, which mature in weeds, may be affected by the reduction of oviposition sites, although severe infestations of the banded fruit weevil Phlyctinus callosus (Shönherr) have been observed in straw mulch layers in blueberry plantations (Bredenhand et al., 2010) and vineyards. In vineyards, predacious mites, which are natural enemies of target pests in vineyards, utilise cover crops as refuge sites (Pringle, 1998). A positive impact on pest management, e.g. reduction of woolly apple aphid populations, was found in apple orchards, in addition to other positive horticultural effects (Damavandian, 2000; Matthews, 2001).
In summary, mulches have the potential to modify the soil community through changes in habitat and microclimate. The aim of this research was to do a preliminary assessment of the effects that various mulches have on a general soildwelling arthropod assemblage in South African vineyards. Based on these findings, further recommendations can be made for a longer, more detailed study.

\section{MATERIALS AND METHODS}

Sampling took place from March to June 2010 (every second week) on four wine grape farms in the Stellenbosch/Paarl region (Table 1). On each farm, two vineyards were selected,

TABLE 1

Description of mulches applied at each site (vineyard) and time of application from March to June 2010.

\begin{tabular}{lll}
\hline SITE & CO-ORDINATES & MULCH \\
\hline 1 & $33^{\circ} 49^{\prime} 68^{\prime} \mathrm{S}, 18^{\circ} 54^{\prime} 92^{\prime} \mathrm{E}$ & Woodchips (2011), put on towards end of monitoring \\
2 & $34^{\circ} 02^{\prime} 40^{\prime \prime} \mathrm{S}, 18^{\circ} 48^{\prime} 011^{\prime} \mathrm{E}$ & Woodchips (2008) \\
3 (Mulch M) & $33^{\circ} 57^{\prime} 00^{\prime} \mathrm{S}, 18^{\circ} 45^{\prime} 23^{\prime} \mathrm{E}$ & Woodchips (2011) \\
3 (Mulch MT) & $33^{\circ} 57^{\prime} 00{ }^{\prime} \mathrm{S}, 18^{\circ} 45^{\prime} 23^{\prime \prime} \mathrm{E}$ & Compost (mostly grape pomace), new dense layer \\
4 & $33^{\circ} 50^{\prime} 15^{\prime} \mathrm{S}, 18^{\circ} 57^{\prime} 12^{\prime \prime} \mathrm{E}$ & Old straw layer, many clear patches of soil in between \\
\hline
\end{tabular}

TABLE 2

Arthropod diversity (families/suborders) caught in pitfall traps in vineyards with and without mulches from March - June 2010. Description of preferred food type in brackets: $\mathrm{H}=$ herbivorous; $\mathrm{P}=$ predatory; $\mathrm{O}=$ omnivorous. Potential pest insects are indicated in bold.

\begin{tabular}{|c|c|c|c|}
\hline MULCH & & NO MULCH & \\
\hline Scientific name & Common name (food group) & Scientific name & Common name (food group) \\
\hline Arthropleona & Elongate springtails (H) & Arthropleona & Elongate springtails (H) \\
\hline Symphypleona & Globular springtails (H) & Symphypleona & Globular springtails (H) \\
\hline Acrididae & Grasshoppers (H) & Acrididae & Grasshoppers (H) \\
\hline Aphididae & Aphids (H) & Anthocoridae & Pirate bugs $(\mathrm{P})$ \\
\hline Apidae & Honey bees $(\mathrm{H})$ & Aphididae & Aphids $(\mathrm{H})$ \\
\hline Bostrychidae & Borer beetles $(\mathrm{H})$ & Asilidae & Robber flies (P) \\
\hline Carabidae & Ground beetles $(\mathrm{P})$ & Bostrychidae & Borer beetles $(\mathrm{H})$ \\
\hline Cecidomyidae & Gall midges $(\mathrm{H})$ & Calliphoridae & Blow flies $(\mathrm{O})$ \\
\hline Curculionidae & Snout beetles $(\mathrm{H})$ & Carabidae & Ground beetles $(\mathrm{P})$ \\
\hline Drosophilidae & Vinegar flies $(\mathrm{H})$ & Chrysomelidae & Leaf beetles $(\mathrm{H})$ \\
\hline Encyrtidae & Parasitic wasps (P) & Cicadellidae & Leafhoppers $(\mathrm{H})$ \\
\hline Formicidae & Ants $(\mathrm{O})$ & Curculionidae & Snout beetles $(\mathrm{H})$ \\
\hline Forficulidae & Common earwigs $(\mathrm{O})$ & Encyrtidae & Parasitic wasps (P) \\
\hline Gryllidae & Crickets $(\mathrm{O})$ & Flatidae & Moth bugs (H) \\
\hline Labiduridae & Long-horned earwigs (O) & Forficulidae & Common earwigs $(\mathrm{O})$ \\
\hline Meloidae & CMR beetles $(\mathrm{P})$ & Formicidae & Ants $(\mathrm{O})$ \\
\hline Muscidae & House flies (H) & Gryllidae & Crickets $(\mathrm{O})$ \\
\hline Myrmeliontidae & Antlions (P) & Lepismatidae & Silverfish $(\mathrm{O})$ \\
\hline Nitidulidae & Nitidulids (O) & Muscidae & House flies (H) \\
\hline Pentatomidae & Stink bugs $(\mathrm{H})$ & Pentatomidae & Stink bugs $(\mathrm{H})$ \\
\hline Phoridae & Coffin flies (O) & Phoridae & Coffin flies (O) \\
\hline Psocoptera & Booklice $(\mathrm{H})$ & Pyrrhocoridae & Cotton stainers $(\mathrm{H})$ \\
\hline Pteromalidae & Pteromalids (P) & Reduviidae & Assassin bugs (P) \\
\hline Pyrrhocoridae & Cotton stainers $(\mathrm{H})$ & Scarabaeidae & Dung beetles (H) \\
\hline Reduviidae & Assassin bugs (P) & Scelionidae & Parasitic wasps (P) \\
\hline
\end{tabular}


TABLE 2 (CONTINUED)

\begin{tabular}{llll}
\hline Scarabaeidae & Dung beetles $(\mathrm{H})$ & Tenebrionidae & Darkling beetles $(\mathrm{O})$ \\
Scelionidae & Parasitic wasps $(\mathrm{P})$ & Tephritidae & Fruit flies $(\mathrm{H})$ \\
Sciaridae & Fungus gnats $(\mathrm{H})$ & Tettigoniidae & Grasshoppers $(\mathrm{O})$ \\
Staphylinidae & Rove beetles $(\mathrm{P})$ & & \\
Tenebrionidae & Darkling beetles $(\mathrm{O})$ & & \\
Tephritidae & Fruit flies $(\mathrm{H})$ & & \\
Tettigoniidae & Grasshoppers $(\mathrm{O})$ & & \\
\hline
\end{tabular}
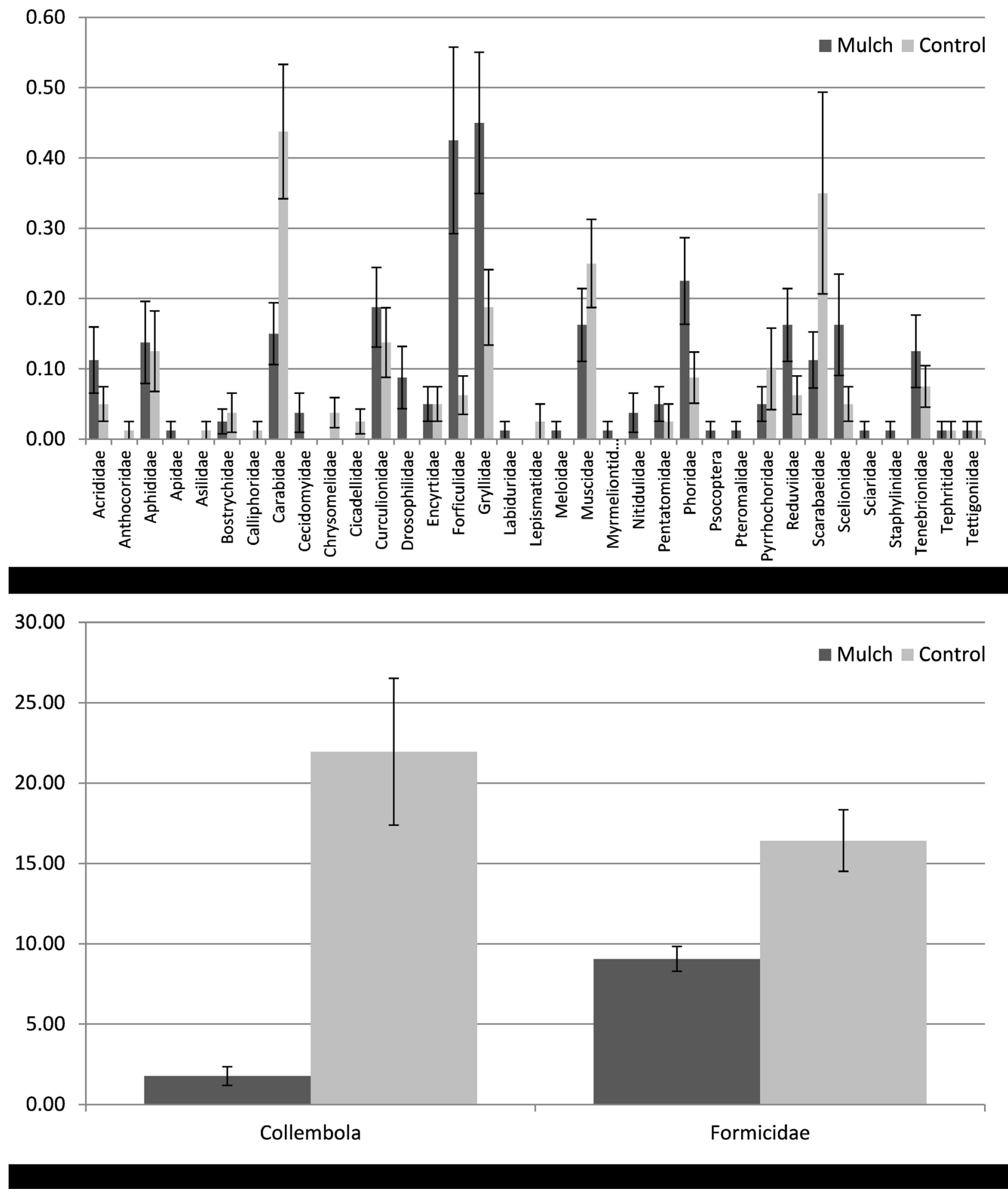

FIGURE 1

Mean number $( \pm$ SE) of insects and springtails found in control (no mulch) and mulched vineyards from March to June 2010 using pitfall traps. The bottom graph represents springtails and ants, while the top graph represents all other insect groups. 
one with mulch and one without mulch (control), in which a standard weed control programme was followed. All control sites were relatively weed free at the time of sampling, as it was at the end of summer just before the winter rains. On one of the farms (site 3), one additional mulch plot was included. Each plot was approximately one hectare in size. Monitoring included the use of pitfall traps, which are the most widely used sampling method for arthropods active on the soil surface (Woodcock, 1997). A total of 20 traps were used per vineyard, with five traps in four rows, evenly spaced and placed on the berm adjacent to a vine. Each trap consisted of a polystyrene test tube $(18 \times 150 \mathrm{~mm})$ containing approximately $4 \mathrm{~mL}$ of seven parts $70 \%$ ethyl alcohol and three parts pure glycerol, similar to those described by Majer (1978). The test tubes were sunk into holes in the ground prepared with a metal rod, while the soil was levelled around the test tubes so that the edge was even with the soil surface. All arthropods (Collembola and Insecta) sampled were identified to family level. Cluster analysis (Statistica v. 10, Statsoft South Africa) was used to represent the arthropod composition in each vineyard sampled.

\section{RESULTS AND DISCUSSION}

A total of forty different families of springtail (Collembola) and insect (Insecta) were recorded. More pest insects were found in the control (no mulch) sites than in the mulched sites (Table 2). There was a greater diversity of arthropods in the mulch sites than in the control sites when the data were combined (Table 2), while insect abundance was similar in the control and mulch sites (average of 1.5 and 1.6 respectively).

Springtails (Arthropleona and Symphypleona) and ants were separated from the other insect families due to the difference in scale of abundance (Fig. 1). The abundance of both springtails and ants was higher in the control sites than in the mulch sites. Springtails are common prey for many predators (notably earwigs and assassin bugs), which were in greater abundance in the mulch sites, potentially resulting in the reduced numbers of springtails in these sites. Ants and dung beetles (Scarabaeidae) have often been referred to as good bioindicators of disturbance, habitat quality and land use (Samways et al., 2010), while springtails have been used largely as indicators in soil ecosystems (Greenslade, 2007). These taxa could therefore be used in future studies as indicator species for testing the effect of mulches on soil health in vineyards.

Egg parasitoids in the family Scelionidae were higher in the mulch sites, as was also found by Thomson and Hoffmann (2007). Their role as natural enemies in South African vineyards is poorly documented. The family Encyrtidae (mealybug parasitoids) were represented in the pitfall traps, although their numbers were very low. This indicates that these parasitoids do forage on the vineyard floor and that mulches could potentially act as a refuge for these insects. There was no difference in encyrtids between the mulch and control sites. Aphids (Aphididae) and leafhoppers (Cicadellidae) were the most abundant potential pest species in this study, with leafhoppers being more abundant in the control sites, while aphids were similar in both the mulch and control sites.

According to the cluster analysis (Fig. 2), the mulch sites were indeed grouped together, showing a high degree of similarity of these sites, based on arthropod diversity from the pitfall traps. This, in turn, indicates that the mulch sites did affect this assemblage in a way that could be detected statistically. Long-term monitoring of insect assemblages should yield valuable data for future vineyard management strategies.

Insect abundances were also classified to functional feeding groups (Fig. 3). Significantly higher numbers of omnivores (paired t-test, $\mathrm{n}=80, \mathrm{p}<0.001$ ) occurred in mulched sites compared to control sites, while herbivores, predators and parasitoids were not significantly different between the mulch and control sites.

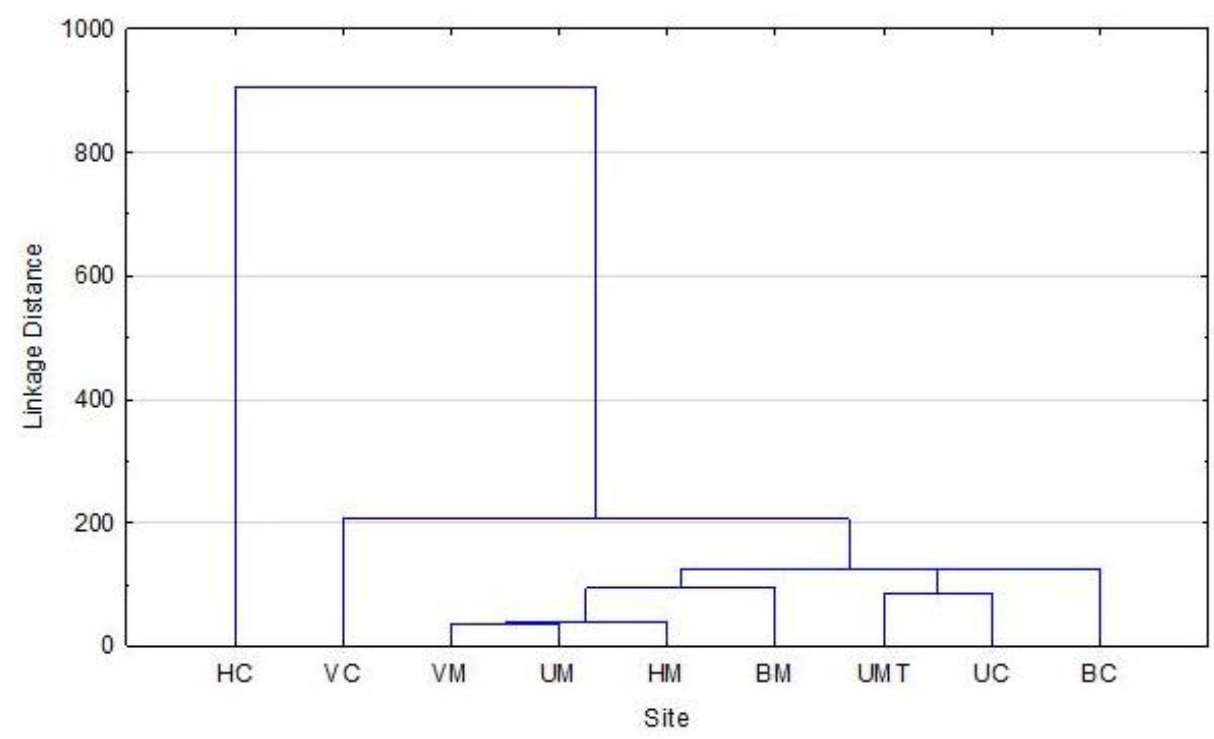

FIGURE 2

Mean number $( \pm \mathrm{SE}$ ) of insects found in control (no mulch) and mulched vineyards from March to June 2010 using pitfall traps, divided into functional feeding groups (springtails and ants are excluded). 


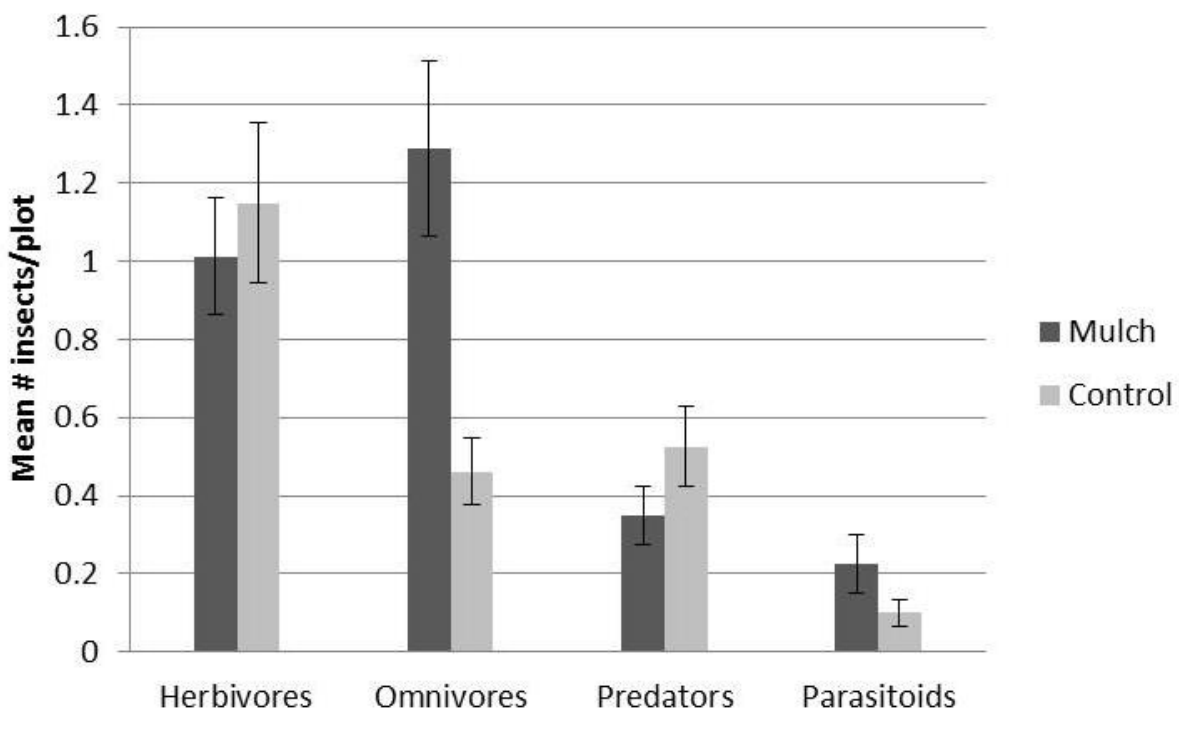

FIGURE 3

Cluster analysis indicating linkage distances per site, based on arthropod diversity in each site. Vineyards: $\mathrm{B}=\mathrm{Site} 1 ; \mathrm{H}=$ Site 2; $\mathrm{U}=$ Site 3; $\mathrm{V}=$ Site 4. Treatments: $\mathrm{C}=$ control (no mulch); $\mathrm{M}$ and $\mathrm{MT}=$ mulch.

\section{CONCLUSIONS}

As a preliminary investigation into differences in arthropod diversity in mulch and control vineyards in South Africa, this study showed some promising results. In line with other studies (Brown \& Tworkoski, 2004; Gaigher, 2008; Thomson $\&$ Hoffman, 2007), higher arthropod diversity and fewer pest species were found in the mulched plots than in the control plots. Also, significantly more omnivorous species were found in the mulched plots than in the control plots.

Predatory interactions play a significant role in determining species composition. This was also found by Gaigher (2008), working in South African vineyards, and by Thomson and Hoffmann (2007), working in Australian vineyards. They recommend that a predator/prey interaction would be useful to explain the ultimate value of mulches. The vine mealybug, with its parasitoids and associated ants, could be used as a study system representing one such tritrophic interaction to highlight the effects that mulches could have in vineyards. However, our methods were not suitable to investigate this system in total.

Pitfall traps were found to be very useful in determining species diversity in these sites, and in highlighting differences between sites. However, they were not suitable for sampling mealybugs, the major pest in vineyards, in this trial. Therefore it is recommended that additional sampling methods also be incorporated, such as sticky traps and arboreal sampling.

A study over at least two seasons would result in obtaining data highlighting seasonal influences (De Villiers \& Pringle, 2007). Our study did not include a pre-sampling period before the mulches were applied. If this had been documented, trends in insect populations could have been detected. Our study nonetheless provides a good baseline that can be used to plan a full-scale study in the future.

\section{LITERATURE CITED}

Addison, P. \& Samways, M.J., 2006. Surrogate habitats demonstrate the invasion potential of the African pugnacious ant. Biodivers. Conserv. 15, $411-428$
Altieri, M.A., 1999. The ecological role of biodiversity in agroecosystems. Agricult. Ecosys. Environ. 74(1-3), 19-31.

Altieri, M.A. \& Nicholls, C.I., 2003. Soil fertility management and insect pests: harmonizing soil and plant health in agroecosystems. Soil Till. Res. $72,203-211$

Bredenhand, E., Van Hoorn, A., May, F., Ferreira, T. \& Johnson, S., 2010. Evaluation of techniques for monitoring banded fruit weevil, Phlyctinus callosus (Schoenherr) (Coleoptera: Curculionidae), infestation in blueberry orchards. Afr. Entomol. 18(1), 205-209.

Brown, M.W. \& Tworkoski, T., 2004. Pest management benefits of compost mulch in apple orchards. Agricult. Ecosys. Environ. 103, 465-472.

Cook, H.F., Valdes, G.S.B. \& Lee, H.C., 2006. Mulch effects on rainfall interception, soil physical characteristics and temperature under Zea mays L. Soil Till. Res. 91(1-2), 227-235.

Damavandian, M.R., 2000. Biology of subterranean populations of woolly apple aphid, Eriosoma lanigerum (Hausmann), in apple orchards. $\mathrm{PhD}$ dissertation, Stellenbosch University, Private Bag X1, 7602 Matieland (Stellenbosch), South Africa.

De Villiers, M. \& Pringle, K.L., 2007. Seasonal occurrence of vine pests in commercially treated vineyards in the Hex River Valley in the Western Cape Province, South Africa. Afr. Entomol. 15(2), 241-260.

Flint, M.L., 2012 ( $2^{\text {nd }}$ ed). IPM in practice: Principles and methods of integrated pest management. University of California, Davis, USA.

Gaigher, R., 2008. The effect of different vineyard management systems on the epigaeic arthropod assemblages, in the Cape Floristic Region, South Africa. MSc thesis, Stellenbosch University, Private Bag X1, 7602 Matieland (Stellenbosch), South Africa.

Greenslade, P., 2007. The potential of Collembola to act as indicators of landscape stress in Australia. Aust. J. Exp. Agric. 47, 424-434.

Henle, K., Alard, D., Clitherow, J., Cobb, P., Firbank, L., Kull, T., McCracken, D., Moritz, R.F.A., Niemelä, J., Rebane, M., Wascher, D., Watt, A. \& Young, J., 2008. Identifying and managing the conflicts between agriculture and biodiversity conservation in Europe - A review. Agricult. Ecosys. Environ. 124(1-2), 60-71.

Kim, K.C. \& Weaver, R.D., 1994 (1 ${ }^{\text {st }}$ ed). Biodiversity and landscapes: A paradox of humanity. Cambridge University Press, Cambridge, U.K. 
Majer, J.D., 1978. An improved pitfall trap for sampling ants and other epigaeic invertebrates. J. Aust. Entomol. Soc. 17, 261-262.

Matthews, C.R., 2001. Integrated pest management aspects of organic mulch in apple orchards. ESA 2001 Annu. Meet., Abstracts.

Pringle, K.L., 1998. Biological control of tetranychid mites in South African apple orchards. Proc. 10th Int. Conf. of Acarology, MONTH?, Canberra, Australia. pp. $429-435$.

Ramakrishna, A., Tam, H.M., Wani, S.P. \& Long, T.D., 2006. Effect of mulch on soil temperature, moisture, weed infestation and yield of groundnut in northern Vietnam. Field Crop Res. 95(2-3), 115-125.

Samways, M.J., New, T.R. \& McGeoch, M.A., 2010. Insect conservation: A handbook of approaches and methods. University Press, Oxford.

Sandhu, H.S., Wratten, S.D. \& Cullen, R., 2010. Organic agriculture and ecosystem services. Environ. Sci. Policy 13, 1-7.

Shangning, J. \& Unger, P.W., 2001. Soil water accumulation under differen precipitation, potential evaporation, and straw mulch conditions. Soil Sci. Soc. Am. J. 65(2), 442-448.
Smith, R., 2007. Compost grape pomace to remove risk of spreading mealybugs. SC Vit. Newsletter, December, 2-4.

Stern, V.M., Smith, R.F., Van den Bosch, R. \& Hagen, K.S., 1959. The integrated control concept. Hilgardia 29, 81-101.

Thomson, L.J. \& Hoffmann, A.A., 2007. Effects of ground cover (straw and compost) on the abundance of natural enemies and soil macro invertebrates in vineyards. Agric. for Entomol. 9, 173-179.

Tilman, D., Cassman, G.K., Matson, P.A., Naylor, R. \& Polasky, S., 2002. Agricultural sustainability and intensive production practices. Nature 418, 671-677.

Wardle, D.A., Bardgett, R.D., Klironomos, J.N., Setäla, H., Van der Putten, W.H. \& Wall, D.H., 2004. Ecological linkages between aboveground and belowground biota. Science 304, 1629-1633.

Woodcock, B.A., 1997. Pitfall trapping in ecological studies. In: Leather, S. (ed). Insect sampling techniques in forest ecosystems. Blackwell Publishing, Oxford. Chapter 3, 37-57.

Zehnder, G., Gurr, G.M., Kuhne, S., Wade, M.R., Wratten, S.D. \& Wyss, E., 2007. Arthropod pest management in organic crops. Annu. Rev. Entomol. $52,57-80$. 